\title{
Morita-Baylis-Hillman Reaction. A Caveat
}

\author{
Veejendra K. Yadav* \\ Department of Chemistry, Indian Institute of Technology Kanpur, Kanpur 208016, India \\ vijendra@iitk.ac.in
}

\begin{abstract}
It is an oversight to consider that a Lewis base such as a trialkylamine adds to an activated alkene in conjugate fashion to generate an enolate as a 1,5-zwitterion, which next reacts in aldol fashion with an electrophile such as an aldehyde to move on further through other events to the Morita-Baylis-Hillman product. It is demonstrated from computational investigations that the union of trialkylamine and activated alkene leads possibly to a very low level charge-transfer entity, wherein the $\pi$-electron density of the alkene has little perturbed to call it an enolate in the conventional sense. It is suggested to consider the aldol reaction as the first step of the Morita-Baylis-Hillman reaction and arrive at the corresponding transition state structure directly from the three entities.
\end{abstract}

KEYWORDS: Morita-Baylis-Hillman reaction, trialkylamine, conjugate addition, enolate, aldol reaction

\section{Introduction}

Morita-Baylis-Hillman ( $\mathrm{MBH}$ ) reaction is an atom-economic green reaction that allows coupling of an activated alkene with an electrophile to result in a multi-functional product for exploitation by synthetic organic chemists. ${ }^{1-3}$ Reaction is generally carried out simply by mixing the activated alkene and electrophile in the presence of a trialkylamine as catalyst, with or without a solvent, at low temperatures. The ease of conducting the reaction and also the great utility of the resultant product has prompted extensive exploration over the past four decades to expand the substrate and catalyst scope. ${ }^{4-12}$ The asymmetric version of the reaction has been developed by using either specifically designed catalysts or chiral electrophiles for the aldol process. ${ }^{13-15}$ Efforts have also been expended to understand the mechanism of the reaction to aid the design of asymmetric versions for greater synthetic exploitation. ${ }^{16-22}$

It has been argued that the $\mathrm{MBH}$ reaction is initiated by the conjugate addition of a nucleophilic amine to an activated alkene and an enolate is formed. This enolate then enters aldol reaction with an electrophile such as an aldehyde to generate an alcoholate, which undergoes proton-transfer and E1CB reactions, in that order, to yield the product along with 
release of the amine. The proton-transfer has lately been demonstrated to take place via a lower energy seven-membered transition state structure as shown in Scheme 1 by taking 2cyclopentenone $\mathbf{1}$ as the activated alkene, acetaldehyde $\mathbf{4}$ as the electrophilic aldol partner and trimethylamine $\mathbf{2}$ as the nucleophilic amine catalyst. ${ }^{21,22}$ The ammonium ylide 6 formed from proton-transfer undergoes Hofmann elimination to form the product 7 and the catalyst is released to re-enter the reaction cycle.

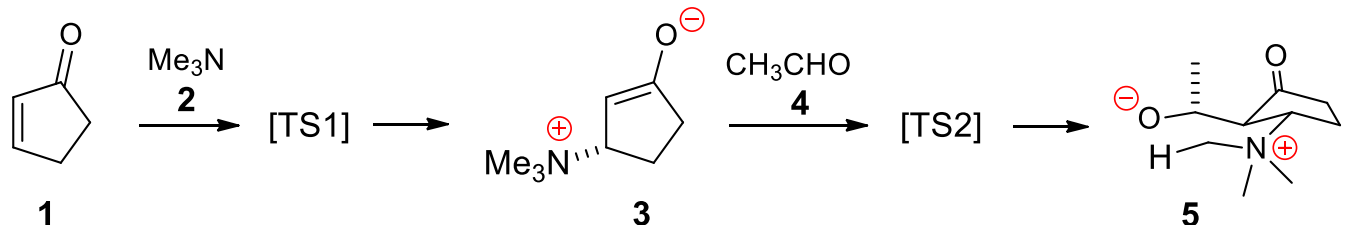

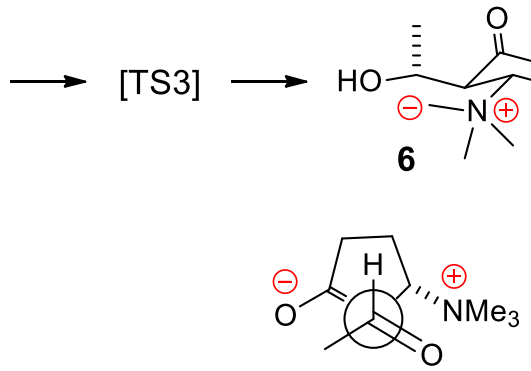

TS2

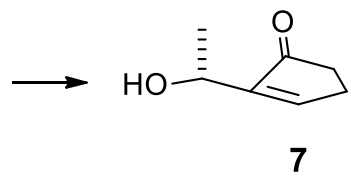

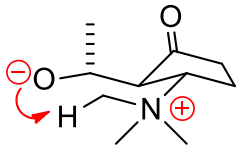

TS3

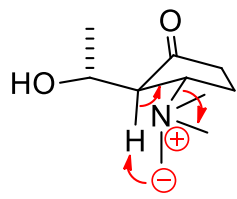

TS4

Scheme 1. MBH reaction involving proton-transfer via a seven-membered transition state structure. TS1 = TS structure for conjugate addition of $\mathrm{Me}_{3} \mathrm{~N}$ to 2-cyclopentenone, $\mathrm{TS2}=\mathrm{TS}$ structure for aldol reaction, TS3 $=$ TS structure for proton transfer, TS4 $=$ TS structure for Hofmann elimination

Computational methods: All the geometry optimizations and TS structure searches were carried out using the global hybrid meta-GGA M06-2X density functional and $6-311++G(d, p)$ basis set at $298.15 \mathrm{~K}$ under $1.0 \mathrm{~atm}$ pressure..$^{23}$ The optimized structures were verified as minima or first order saddle points on their potential energy surfaces by harmonic vibrational frequency analysis. The solvent effects on the reaction profile were estimated using the Conductor Polarized Continuum Model (CPCM). ${ }^{24,25}$ All the energies reported herein are Gibbs free energies (sum of electronic and thermal free energies) expressed in $\mathrm{kcal} / \mathrm{mol}$. Calculations were carried out using the Gaussian 16 suite of programs. ${ }^{26}$

\section{Results and Discussion}

During the course of our investigations of the mechanism of $\mathrm{MBH}$ reaction, we noticed that the new carbon-nitrogen bond in the projected enolate was excessively long and there was hardly any perturbation in the electron density of the enone function, whether the reaction 
was studied in the gas phase or under solvent effects for the subtle change in $\pi_{\mathrm{c}=\mathrm{c}}$ bond length. The lengths of $\pi_{\mathrm{C}=\mathrm{C}}$ bonds in 2-cyclopentenone, the corresponding $\pi_{\mathrm{C}=\mathrm{C}}$ bonds and also the new $\sigma_{\mathrm{C}-\mathrm{N}}$ bonds in the apparent enolates generated from the reactions of 2cyclopentenone with $\mathrm{Me}_{3} \mathrm{~N}, \mathrm{DABCO}$ and $\mathrm{Me}_{2} \mathrm{NOH}$ in the gas phase and under different solvent effects are collected in Table 1 . We have recently reported $\mathrm{Me}_{2} \mathrm{NOH}$ as a superior catalyst for $\mathrm{MBH}$ reaction and implicated the $\alpha$-effect of oxygen on the nitrogen as the cause for its improved nucleophilicy. ${ }^{27}$

Table 1. The $\sigma_{C-N}$ and $\pi_{C=C}$ distances $(\AA)$ in the enolate versus $\pi_{C=c}$ in enone in 2-cyclopentenone in reactions with $\mathrm{Me}_{3} \mathrm{~N}, \mathrm{DABCO}$ and $\mathrm{Me}_{2} \mathrm{NOH}$ in the gas phase and also under solvent effects

\begin{tabular}{|l|l|l|l|l|}
\hline Phase & Catalyst & $\pi_{\mathrm{c}=\mathrm{c}}$ (enone) & $\pi_{\mathrm{c}=\mathrm{c}}$ (enolate) & $\sigma_{\mathrm{c}-\mathrm{N}}$ (enolate) \\
\hline Gas & $\mathrm{Me}_{3} \mathrm{~N}$ & 1.3339 & 1.3357 & 3.0611 \\
\hline $\mathrm{CH}_{3} \mathrm{CN}$ & $\mathrm{Me}_{3} \mathrm{~N}$ & 1.3369 & 1.3386 & 3.0452 \\
\hline DMSO & $\mathrm{Me}_{3} \mathrm{~N}$ & 1.3370 & 1.3387 & 3.0448 \\
\hline THF & $\mathrm{Me}_{3} \mathrm{~N}$ & 1.3365 & 1.3382 & 3.0509 \\
\hline DCM & $\mathrm{Me}_{3} \mathrm{~N}$ & 1.3366 & 1.3383 & 3.0494 \\
\hline gas & $\mathrm{DABCO}$ & 1.3339 & 1.3358 & 3.0350 \\
\hline DMSO & $\mathrm{DABCO}$ & 1.3370 & 1.3388 & 3.0333 \\
\hline gas & $\mathrm{Me}_{2} \mathrm{NOH}$ & 1.3339 & 1.3356 & 3.0694 \\
\hline DMSO & $\mathrm{Me}_{2} \mathrm{NOH}$ & 1.3370 & 1.3382 & 3.1165 \\
\hline DCM & $\mathrm{Me}_{2} \mathrm{NOH}$ & 1.3366 & 1.3378 & 3.1318 \\
\hline
\end{tabular}

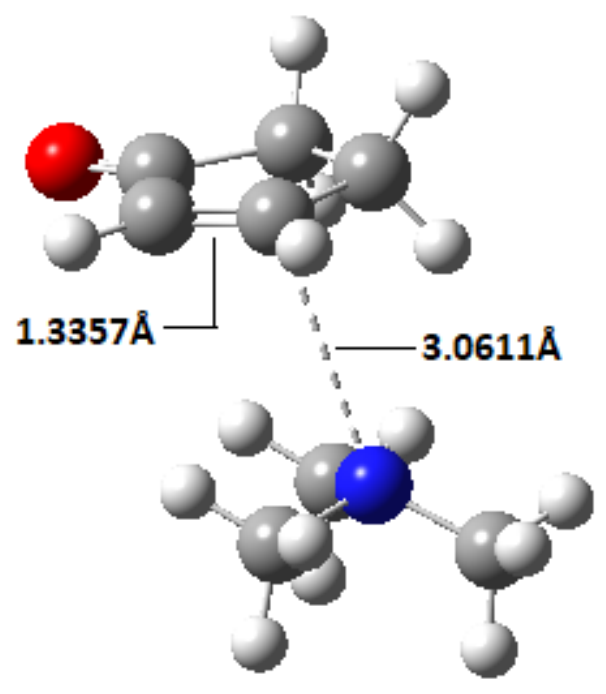

Figure 1. The computed enolate formed from the conjugate addition of $\mathrm{Me}_{3} \mathrm{~N}$ to 2-cyclopentenone in the gas phase (the $\pi_{\mathrm{c}=\mathrm{c}}$ bond length in 2-cyclopentenone alone is $1.3339 \AA$ ) 
It can be seen from the data in the table that the $\sigma_{\mathrm{C}-\mathrm{N}}$ bond distances are always too long and the $\pi_{\mathrm{C}=\mathrm{C}}$ bond in the enolate differs little from the corresponding $\pi_{\mathrm{C}=\mathrm{C}}$ bond in 2cyclopentenone. Due to this little change in $\pi_{\mathrm{c}=\mathrm{c}}$ bond length before and after the reaction with amine, the perturbation in enone electron density is little to qualify for what we typically consider enolate. The bond distances in the computed enolate for the reaction of $\mathrm{Me}_{3} \mathrm{~N}$ with 2-cyclopentenone are given in Figure 1 to illustrate the point.

The situation with acyclic activated alkenes is similar to that of the cyclic activated alkene above. The relevant data from the reactions of methyl acrylate and acrylonitrile with catalysts such as DABCO and $\mathrm{Me}_{3} \mathrm{~N}$ are collected in Table 2. The $\sigma_{\mathrm{C}-\mathrm{N}}$ distances are too long and $\pi_{\mathrm{C}=\mathrm{C}}$ distances in the enolates are hardly any different from those in the activated alkenes. The change in delocalization of the enone electron density in the proposed enolate being little, its formation could be arguably doubted.

Table 2. The $\sigma_{C-N}$ and $\pi_{C=C}$ distances $(\AA)$ in the enolate versus $\pi_{C=C}$ in select activated acyclic alkenes in reactions with $\mathrm{DABCO}$ and $\mathrm{Me}_{3} \mathrm{~N}$ in the gas phase and also under solvent effects

\begin{tabular}{|l|l|l|l|l|l|}
\hline Alkene & Phase & Catalyst & $\pi_{\mathrm{c}=\mathrm{c}}$ (alkene) & $\pi_{\mathrm{c}=\mathrm{c}}$ (enolate) & $\sigma_{\mathrm{c}-\mathrm{N}}$ (enolate) \\
\hline methyl acrylate & Gas & DABCO & 1.3279 & 1.3295 & 2.9874 \\
\hline methyl acrylate & DMSO & DABCO & 1.3289 & 1.3300 & 3.0942 \\
\hline methyl acrylate & $\mathrm{CH}_{3} \mathrm{CN}$ & $\mathrm{BADCO}$ & 1.3289 & 1.3300 & 3.0930 \\
\hline methyl acrylate & $\mathrm{DCM}$ & $\mathrm{DABCO}$ & 1.3288 & 1.3299 & 3.0574 \\
\hline methyl acrylate & THF & $\mathrm{DABCO}$ & 1.3288 & 1.3299 & 3.0525 \\
\hline acrylonitrile & Gas & $\mathrm{Me}_{3} \mathrm{~N}$ & 1.3299 & 1.3316 & 2.9519 \\
\hline acrylonitrile & DMSO & $\mathrm{Me}_{3} \mathrm{~N}$ & 1.3308 & 1.3325 & 2.9625 \\
\hline
\end{tabular}

Consequently, we consider it appropriate to involve the amine catalyst, activated alkene and electrophile for the crucial aldol reaction in one go rather than the customary step-wise enolate formation and then aldol reaction. To test this hypothesis, we computed this transition state structure from $\mathrm{Me}_{3} \mathrm{~N}, 2$-cyclopentenone and acetaldehyde in the gas phase and discovered it to be $47.5 \mathrm{kcal} / \mathrm{mol}$ higher than the sum of the ground state energies of the three reacting entities. This activation energy is $5.6 \mathrm{kcal} / \mathrm{mol}$ higher than the one computed from the typical enolate. The other features of the reaction mechanism being the same as discussed elsewhere, ${ }^{21}$ the noted raise in activation energy of the aldol reaction truly makes 
it the rate-controlling step under the normal catalytic conditions. The computed transition state structure is shown in Figure 2.

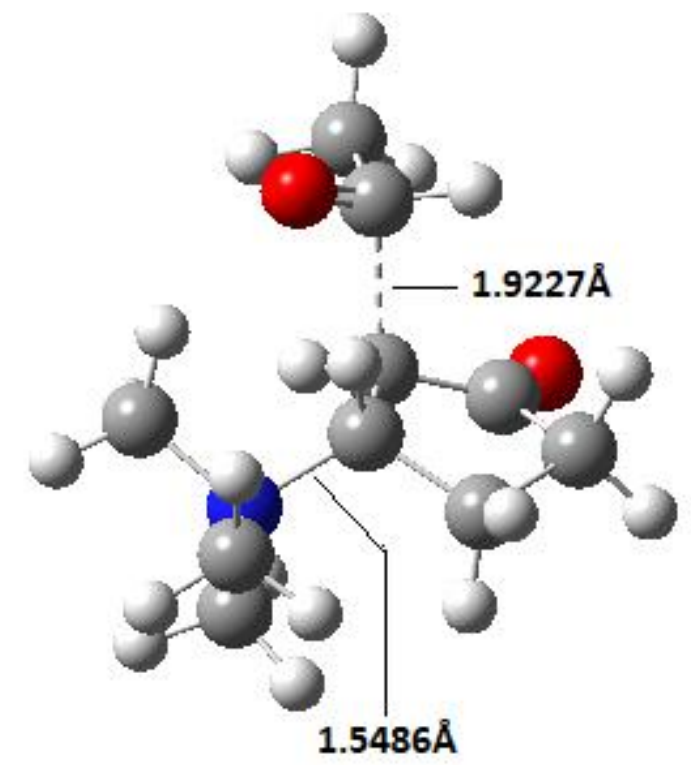

Figure 2. The transition state structure for aldol reaction constructed from $\mathrm{Me}_{3} \mathrm{~N}, 2$-cyclopentenone and $\mathrm{CH}_{3} \mathrm{CHO}$ in the gas phase. $\mathrm{Me}_{3} \mathrm{~N}$ was placed $1.60 \AA$ away from the olefinic carbon in order to allow sufficient perturbation of the $\pi$-electron density in the enone.

\section{Conclusion}

The long-held notion of enolate formation from the conjugate addition of a nucleophilic catalyst (usually a trialkylamine) to an activated alkene as the first step of the MBH reaction is untenable because computations in the gas phase and also under solvent effects reveal little perturbation in the $\pi$-electron density of the alkene for little change in the length of its $\pi_{\mathrm{c}=\mathrm{c}}$ bond. It is advisable to directly approach the transition state structure for aldol reaction by engaging the catalyst, activated alkene and electrophile in one go.

The resultant raise in the activation energy over the follow up reactions in the gas phase as well as under solvent effects truly makes the aldol reaction rate-controlling. ${ }^{28}$

\section{ASSOCIATED CONTENT}

\section{Supporting Information}

Supporting Information (SI) available: Cartesian coordinates of the optimized ground state structures, TS structures and Gibbs free energies 


\section{ORCID}

Veejendra K. Yadav: 0000-0001-8294-0677

\section{ACKNOWLEDGEMENTS}

The author acknowledges allocation of time on HPC series of supercomputers by the Computer Centre, Indian Institute of Technology Kanpur.

\section{REFERENCES}

1. Morita, K.; Suzuki, Z.; Hirose, H. A Tertiary Phosphine-catalyzed Reaction of Acrylic Compounds with Aldehydes. Bull Chem Soc. Jpn. 1968, 41, 2815-2816.

2. Morita, K.; Kobayashi, T. New Addition Reactions of Acrylic Compounds with Fumaric Acid Esters Catalyzed by Tervalent Phosphorus Compounds. Bull Chem Soc Jpn. 1969, 42, 2732-2732.

3. Baylis, A. B.; Hillman, M. E. D. German Patent 1972, 2155113; Chem. Abstr. 1972, 77, 34174q.

4. Basavaiah, D.; Rao, P. D.; Hyma, R. S. The Baylis-Hillman Reaction: A Novel Carbon-Carbon Bond Forming Reaction. Tetrahedron 1996, 52, 8001-8062.

5. Basavaiah, D.; Rao, A. J.; Satyanarayana, T. Recent Advances in the Baylis-Hillman Reaction and Applications. Chem. Rev. 2003, 103, 811-891.

6. Basavaiah, D.; Rao, K. V.; Reddy, R. J. The Baylis-Hillman reaction: a novel source of attraction, opportunities, and challenges in synthetic chemistry. Chem. Soc. Rev. 2007, 36, 1581-1588.

7. Ma, G.-N; Jiang, J.-J.; Shi, M., Wei, Y. Recent extensions of the Morita-Baylis-Hillman reaction. Chem. Commun. 2009, 5496-5514.

8. Basavaiah, D.; Reddy, B. S.; Badsara, S. S. Recent Contributions from the Baylis-Hillman Reaction to Organic Chemistry. Chem. Rev. 2010, 110, 5447-5674.

9. de Souza, R. O. M. A.; Miranda, L. S. M. Recent Advances in the Morita-Baylis-Hillman Reaction Under Microwave Irradiation Mini Rev Org. Chem. 2010, 7, 212-220.

10. Basavaiah, D.; Veeraraghavaiah, G. The Baylis-Hillman reaction: a novel concept for creativity in chemistry Chem. Soc. Rev. 2012, 41, 68-78.

11. Bhowmik, S.; Batra, S. Applications of Morita-Baylis-Hillman Reaction to the Synthesis of Natural Products and Drug Molecules. Curr. Org. Chem. 2014, 18, 3078-3119.

12. Basavaiah, D.; Naganaboina, R. T. The Baylis-Hillman reaction: a new continent in organic chemistry - our philosophy, vision and over three decades of research. New J. Chem. 2018, 42, 14036-14066.

13. Carrasco-Sanchez, V.; Simirgiotis, M. J.; Santos, L. S. The Morita-Baylis-Hillman Reaction: Insights into Asymmetry and Reaction Mechanisms by Electrospray Ionization Mass Spectrometry Molecules 2009, 14, 3989-4021.

14. Wei, Y.; Shi, M. Recent Advances in Organocatalytic Asymmetric Morita-Baylis-Hillman/aza-Morita-BaylisHillman Reactions. Chem. Rev. 2013, 113, 6659-6690.

15. Pellissier, H. Recent developments in the asymmetric organocatalytic Morita-Baylis-Hillman reaction. Tetrahedron 2017, 73, 2831-2861. 
16. Krafft, M. E.; Haxell, T. F. N.; Seibert, K. A.; Abboud, K. A. Mechanistic Implications in the Morita-Baylis-Hillman Alkylation: Isolation and Characterization of an Intermediate. J. Am. Chem. Soc. 2006, 128, 4174.

17. Santos, L. S.; Pavam, C. H.; Almeida, W. P.; Coelho, F.; Eberlin, M. N. Probing the Mechanism of the BaylisHillman Reaction by Electrospray lonization Mass and Tandem Mass Spectrometry. Angew. Chem., Int. Ed. 2004, 43, 4330.

18. Robiette, R.; Aggarwal, V. K.; Harvey, J. N. Mechanism of the Morita-Baylis-Hillman Reaction: A Computational Investigation. J. Am. Chem. Soc. 2007, 129, 15513-15525.

19. Roy, D.; Sunoj, R. B. Ab Initio and Density Functional Theory Evidence on the Rate-Limiting Step in the MoritaBaylis-Hillman Reaction. Org. Lett. 2007, 9, 4873-4876.

20. Plata, R. E.; Singleton, D. A. A Case Study of the Mechanism of Alcohol-Mediated Morita Baylis-Hillman Reactions. The Importance of Experimental Observations. J. Am. Chem. Soc. 2015, 137, 3811-3826.

21. Yadav, V. K. An alternate energy-conserved pathway for the Morita-Baylis-Hillman (MBH) reaction. J. Phys. Org. Chem. 2020 (DOI: 10.1002/poc.4149).

22. Yadav, V. K. A computational study of the Hofmann elimination pathway for the Morita-Baylis-Hillman reaction under DABCO-catalysis. Participation of a bridge-head ylide. J. Phys. Org. Chem. 2021 (DOI: 10.1002/poc.4212).

23. Zhao, Y.; Truhlar, D. G. The M06 suite of density functionals for main group thermochemistry, thermochemical kinetics, noncovalent interactions, excited states, and transition elements: two new functionals and systematic testing of four M06-class functionals and 12 other functionals. Theor. Chem. Acc. 2008, 120, 215-241.

24. Barone, V.; Cossi, M. Quantum Calculation of Molecular Energies and Energy Gradients in Solution by a Conductor Solvent Model. J. Phys. Chem. A 1998, 102, 1995-2001.

25. Cossi, M.; Rega, N.; Scalmani, G.; Barone, V. Energies, structures, and electronic properties of molecules in solution with the C-PCM solvation model. J. Comput. Chem. 2003, 24, 669-681.

26. Frisch et al. Gaussian 16, revision C.01; Gaussian, Inc.: Wallingford CT, 2016 (see the Supporting Information for full citation).

27. Yadav, Veejendra (2021): Hydroxylamine as a Superior Organocatalyst for Morita-Baylis-Hillman Reaction. ChemRxiv. Preprint. https://doi.org/10.26434/chemrxiv.14672691.v1

28. Yadav, Veejendra K. (2021): Proton Transfer and Kinetic Isotope Effect in Morita-Baylis-Hillman Reaction under Solvent Effects. A Detailed Computational Study. ChemRxiv. Preprint. https://doi.org/10.26434/chemrxiv.14214014.v1 